\title{
Ameloblastomatous calcifying ghost cell odontogenic cyst - a rare variant of a rare entity
}

\author{
Harkanwal Preet Singh, MDS ${ }^{1}$ \\ Madhulika Yadav, MDS ${ }^{2}$ \\ Amit Nayar, MDS ${ }^{1}$ \\ Chanchal Verma, MDS ${ }^{3}$ \\ Palak Aggarwal, MDS ${ }^{3}$ \\ Sandeep Kumar Bains, MDS ${ }^{4}$
}

Department of Oral and Maxillofacial Pathology and Microbiology, Swami Devi Dyal Hospital and Dental College, Barwala, Panchkula, Haryana. India

2 Department of Pedodontics and Preventive Dentistry, Faculty of Dental Sciences, King George's Medical University, Lucknow, Uttar Pradesh, India

3 Department of Oral and Maxillofacial Pathology and Microbiology, ITS Dental College, Ghaziabad, Uttar Pradesh, India

4 Department of Oral Medicine and Radiology, Swami Devi Dyal Hospital and Dental College, Barwala, Panchkula, Haryana. India

Corresponding author:

Dr. Harkanwal Preet Singh, MDS

Oral and Maxillofacial Pathology and Microbiology,

Swami Devi Dyal Hospital and Dental College,

Barwala, Panchkula, Haryana, India

Phone: +918570023088

E-mail: hkps0320@gmail.com

\section{Summary}

Calcifying odontogenic cyst (COC) is an uncommon benign cystic neoplasm of odontogenic origin, which shows extensive diversity in its clinico-pathological appearances and biological behavior. It most commonly occurs in broader age group of 1-82 years in anterior part of jaws which is classically described by presence of ghost cells. There are variants of $\mathrm{COC}$ according to clinical, histopathological, and radiological characteristics. Therefore a proper categorization of the cases is needed for better understanding of the pathogenesis of each variant. Here we report a rare case of ameloblastomatous calcifying ghost cell odontogenic cyst in $\mathbf{2 4}$ year old female with brief review of literature. Presence of ameloblastomatous proliferation and impacted canine presented a diagnostic dilemma and was diagnosed by careful radiographic and histopathogical interpretation. Long follow up and more case report are required to shed light on its behaviour as there scarcity of data of this lesion in literature.

Key words: cyst, ghost cells, neoplasm, odontogenic.

\section{Introduction}

Epithelial-lined cysts seldom occur in skeletal bones, because embryonic epithelial rests are normally not found in them. They do, however, occur in the jaws where the majorities are lined by epithelium derived from remnants of the odontogenic apparatus. These odontogenic cysts are classified as either of developmental or inflammatory origin. The calcifying ghost cell odontogenic cyst (CGCOC) is a rare example of a developmental odontogenic cyst, its occurrence constituting about $0.37 \%$ to $2.1 \%$ of all odontogenic tumors (1). The calcifying ghost cell odontogenic cyst (CGCOC) was first described by Gorlin et al. who were impressed by the significant presence of the so-called ghost cells (2). At that time, they suggested that this cyst may represent the oral counter part of the dermal calcifying epithelioma of Malherbe $(3,4)$. Over the years since its first description, it has become clear that the calcifying ghost cell odontogenic cyst (CGCOC) has a number of variants, including features of a benign odontogenic tumor. It was classified as SNOMED code 9301/0, in the World Health Organization's (WHO) publication Histological Typing of Odontogenic Tumors (5). WHO in 2005 have classified all COCs under the category of odontogenic tumours (6). One of the histological features of the condition is the presence of ghost cells. Fejeskov and Krough are of the opinion that the lesion initially presents as a solid tumor, consisting mainly of ghost cells and that the cyst development is a secondary phenomenon. They suggested a new descriptive term of ghost cell odontogenic tumor for the lesion (7). We hereby, present a rare case report of ameloblastomatous calcifying ghost cell odontogenic cyst in 24 year old female.

\section{Case report}

24 year old female patient reported with the chief complaint of swelling on left side of face since 6 months. Patient was apparently asymptomatic 6 months back then she noticed a pea sized swelling intra-orally in buccal vestibule in 33, 34 region. Swelling gradually increased in size and manifested extra-orally on face. No associated pain or paraesthesia was present.

General physical examination revealed that the patient was moderately built and nourished. All the vital signs were within normal limits. Extra-oral examination revealed a firm swelling with normal coloured overlying skin on the left lower third of the face extending from corner of mouth to line joining outer can thus of eye to inferior border of mandible (Fig. 1). None of the lymph nodes were palpable. 


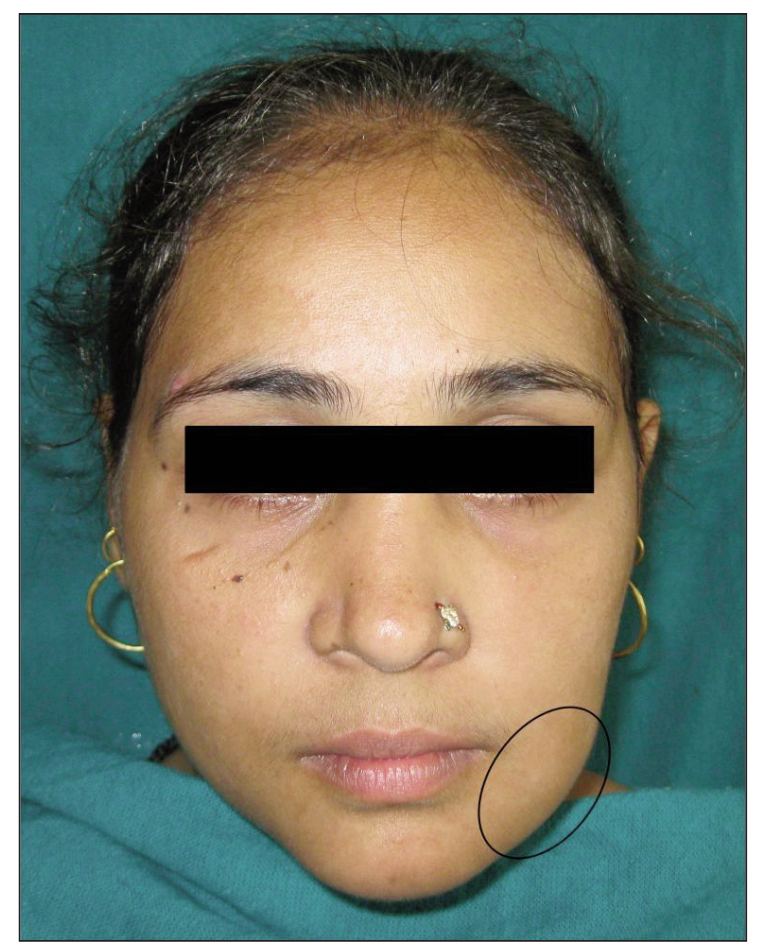

Figure 1. Extra-oral photograph showing a swelling extending from corner of mouth to line joining outer can thus of eye to inferior border of mandible.

Intra-oral examination revealed solitary well defined painless swelling measuring $5 \mathrm{~cm} \times 3 \mathrm{~cm}$, ovoid in shape, firm in consistency, smooth texture with intact overlying mucosa (Fig. 2).

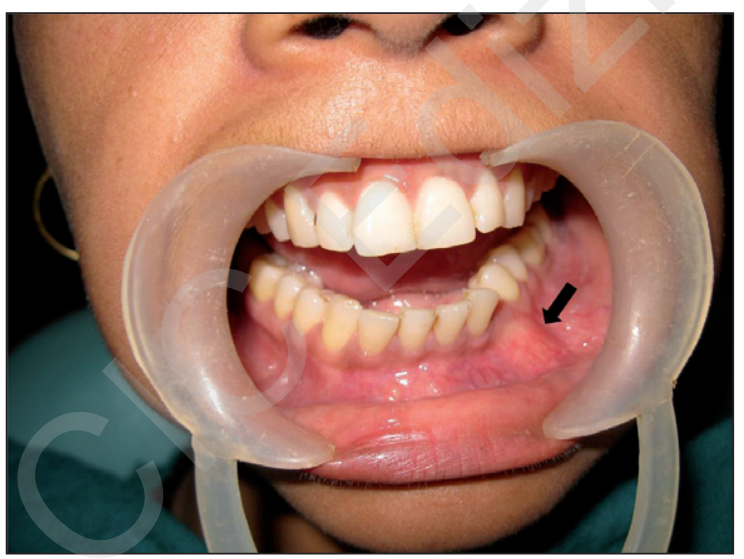

Figure 2. Intra-oral photograph showing solitary well defined swelling (large black arrow) measuring $5 \mathrm{~cm} \times 3 \mathrm{~cm}$, ovoid in shape with intact overlying mucosa.

In roentenographic examination orthopantomograph showed a solitary well defined radiolucency with sclerotic margins extending from 38 to distal aspect of 45 . Superiorly it extends up to alveolar process and inferiorly to $2 \mathrm{~mm}$ above the inferior border of mandible. It also showed impacted 33 (Fig. 3). Mandibular occlusal radiograph reveals well defined radiolucency in mandibular anterior re-

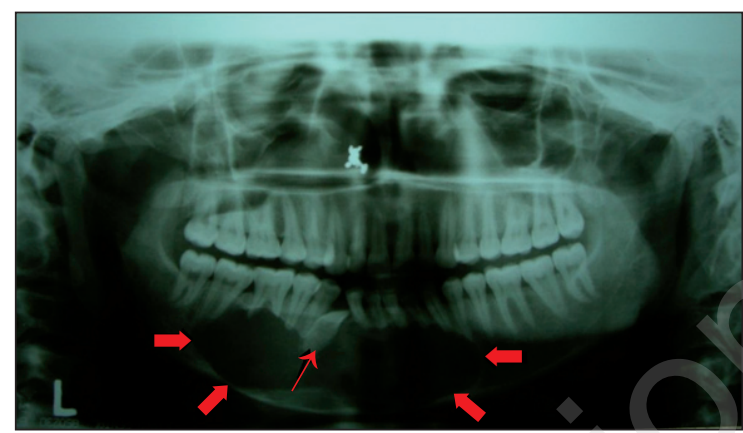

Figure 3. Orthopantomograph demonstrating a solitary well defined radiolucency (large red arrow) with sclerotic margins extending from 38 to distal aspect of 45 and impacted 33 (small red arrow).

gion with buccal and lingual cortical plate expansion (Fig. 4). Axial Computed tomography (CT) scan showed expansion of the tumour mass with thinning of cortical outline (Fig. 5). 3-Dimensional computed tomography volumetric reconstruction showed gross bone destruction with specks of calcification in mandibular anterior region (Fig. 6).

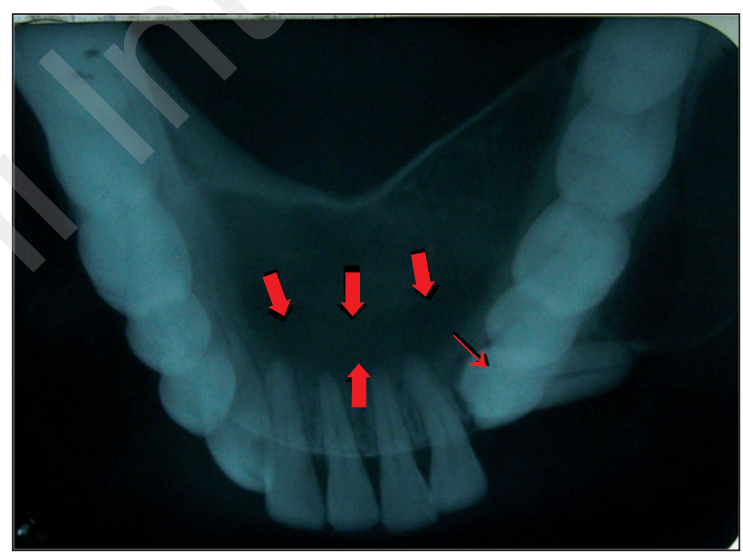

Figure 4. Mandibular occlusal radiograph demonstrating well defined radiolucency (large red arrow) in mandibular anterior region and impacted canine (small red arrow).

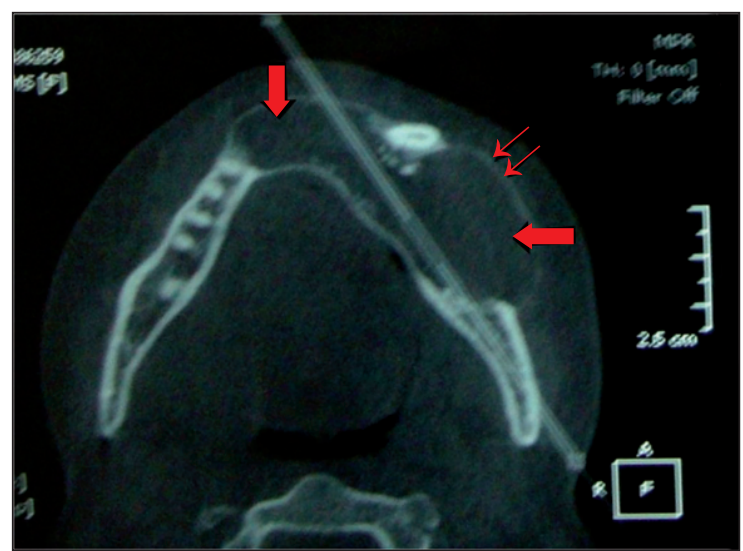

Figure 5. Axial Computed tomography (CT) scan showing expansion of the tumour mass to adjacent soft tissue at the buccal side on soft tissue shadow imaging and expansion (large red arrow), thinning of cortical outline (small red arrow) with large unilocular radiolucency. 


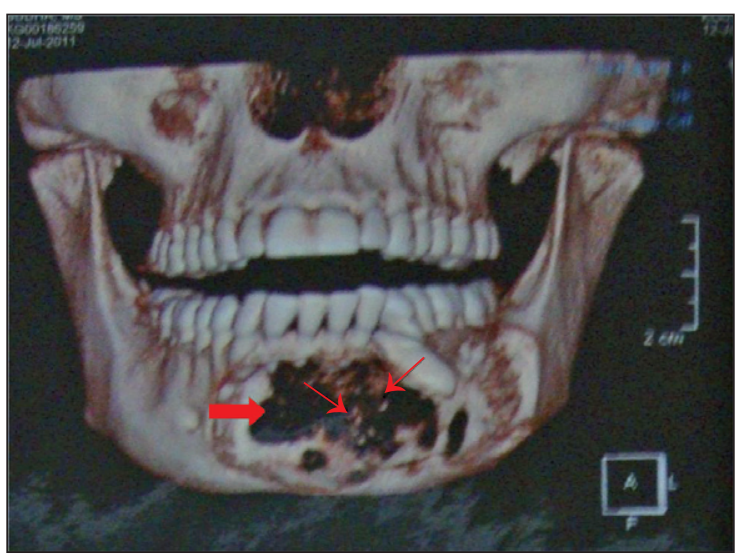

Figure 6. 3-Dimensional CT volumetric reconstruction demonstrated gross bone destruction (large red arrow) with specks of calcification (small red arrow) in mandibular anterior region.

Haematological and urine examinations did not reveal any abnormal findings. Clinical differential diagnosis of dentigerous cyst, ameloblastoma and Calcifying cystic epithelial odontogenic tumour were given.

Incisional biopsy was performed and the tissue was submitted to the Department of Oral Pathology. Histopathologic examination showed 6-8 layered cystic lining composed of prominent basal cell layer with few areas of palisading arrangement. Cells above the basal cell layer are loosely arranged resembling stellate reticulum (Fig. 7).

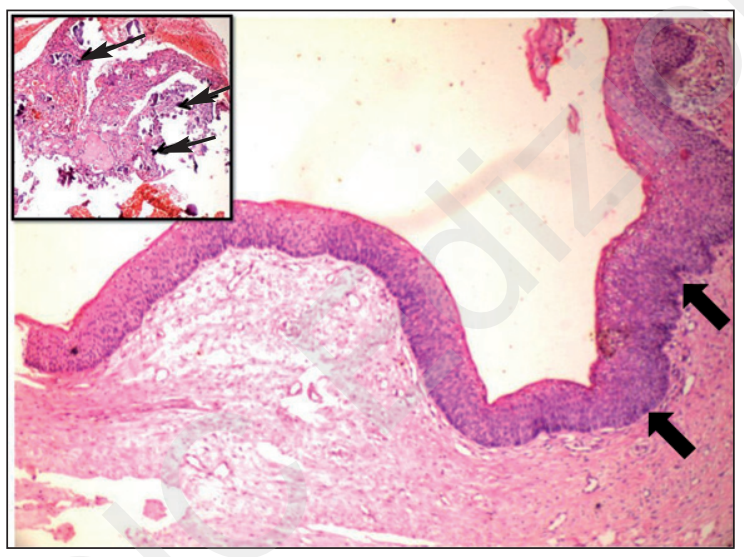

Figure 7. Photomicrograph showing proliferating cystic lining (large balck arrow) with stellate reticulum like areas. (H\&E X10) inset showing spherical to irregular calcification (small balck arrows) (H\&E X10).

Numerous ameloblastic islands along with ghost cells with distinct cell outline and numerous spherical calcifications are seen within the epithelium and connective tissue capsule (Fig. 8). Connective tissue is fibrocellular in nature with chronic inflammatory cells, odontogenic islands, spherical calcifications, few sebaceous nests and few ghost cells with few multinucleated giant cells. Extensive areas of haemorrhage are also evident. Van gieson and masson's trichrome staining was done to differentiate ghost cell from other acidophilic bodies (Fig. 9).

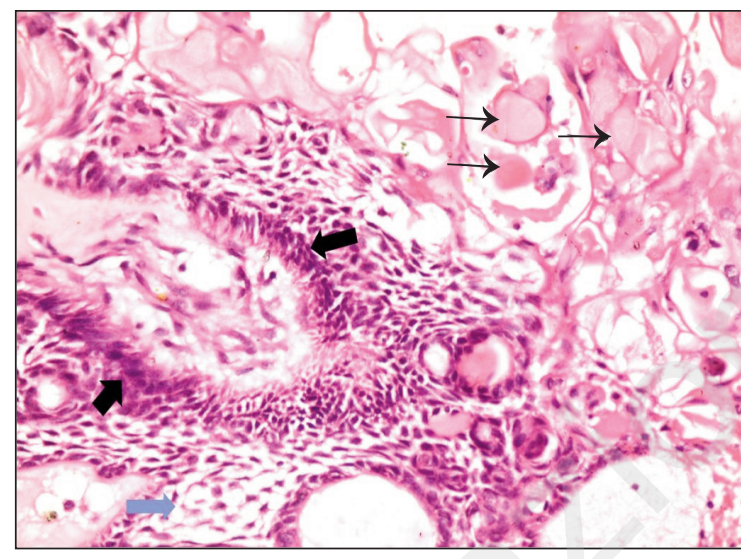

Figure 8. Photomicrograph showing ameloblastic islands(large black arrow) with stellate reticulum like areas (blue arrow) along with numerous ghost cells (small arrow) (H\&E X10).

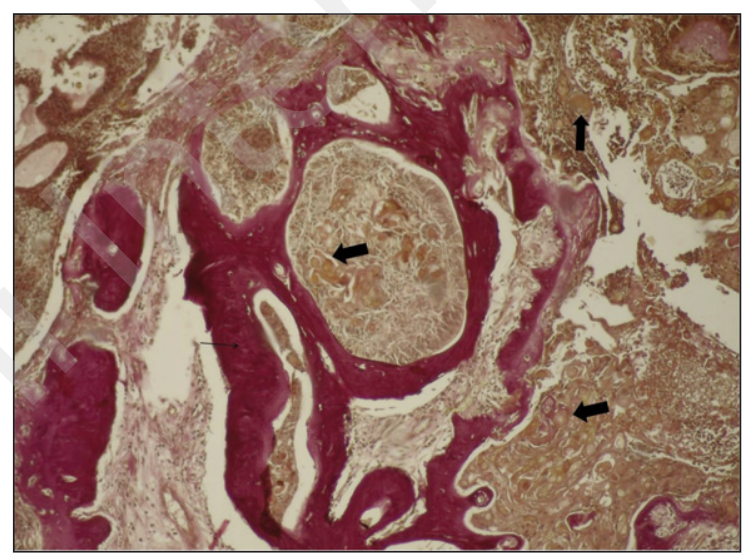

Figure 9. Photomicrograph showing dentinoid (red) and ghost cells (yellow) (Masson's trichrome; x10).

Based on these clinical, radiographic and histopathological features confirmatory diagnosis of Ameloblastomatous Calcifying odontogenic cyst was arrived. The operation was performed under general anaesthesia by enucleation of the lesion and enucleated specimen was cystic approximately $5 \mathrm{~mm}$ to $6 \mathrm{~mm}$ in diameter, entire specimen was sent for histopathological evaluation, and it was reconfirmed as Ameloblastomatous calcifying ghost cell odontogenic cyst. The patient was followed up for 2 years with no evidence of recurrence.

\section{Discussion}

Gorlin and colleagues identified CGCOC as a distinct pathological entity in 1962 although according to Altini and Farman, the condition had previously been described in German literature in 1932 by Rywkind (8). The CGCOC has also been reported under a variety of other designations (Tab. 1).

In 1992, the World Health Organization (WHO) classified CGOC as a neoplasm rather than a cyst but confirmed most of the cases are non-neoplastic. In view of this du- 
Table 1. Terminology of the so-called calcifying odontogenic cyst (9). (Modified from Toida 2008)

\begin{tabular}{lll}
\hline Gorlin et al. & 1962 & Calcifying odontogenic cyst \\
\hline Gold & 1963 & Keratinizing calcifying odontogenic cyst (KCOC) \\
\hline Bhaskar & 1965 & Keratinizing ameloblastoma \\
\hline Fejerskov and Krogh & 1972 & Calcifying ghost cell odontogenic tumor (CGCOT) \\
\hline Freedman et al. & 1975 & Cystic calcifying odontogenic tumor (COCT) \\
\hline Praetorius et al. & 1981 & Dentinogenic ghost cell tumor (DGCT) \\
\hline Ellis and Shmookler & 1986 & Epithelial odontogenic ghost cell tumor (EOGCT) \\
\hline Colmenero et al. & 1990 & Odontogenic ghost cell tumor (OGCT) \\
\hline
\end{tabular}

ality, many different terminologies have been applied to cystic and solid CGOC variants, but calcifying odontogenic cyst is the preferred term (9). Several classifications of CGOC subtypes have been proposed, but most of them have limitations in separating cystic and neoplastic variant.

First classification is proposed by Praetorius et al. (3):

- Type 1. Cystic type:

- (A) simple unicystic type,

- (B) odontoma-producing type,

- (C) ameloblastomatous proliferating type.

- Type 2. Neoplastic type: dentinogenic ghost cell tumor.

The odontogenic origin of the CGCOC is widely accepted $(10,11)$. The cells responsible for the calcifying odontogenic cyst are dental lamina rests (rests of Serres) within either the soft tissue or bone. Therefore, calcifying ghost cell odontogenic cysts are cysts of primordial origin and are not associated with the crown of an impacted tooth (12). It most often occurs as a central (intraosseous) lesion $(11,12)$, whereas peripheral (extraosseous) localization in the soft tissue is rare $(13,14)$. It occurs most commonly in $1 \mathrm{yr}-82 \mathrm{yrs}$ of age. There is a distinct peak in the second decade. Equal sex predilection has been observed. Majority of the cases are seen in the jaw bones with equal distribution in maxilla and mandible. Anterior part of the jaws is the commonest site of occurrence (15). In our present case reported COC occurred in 24 year old female patient in anterior region of mandible which falls well within the data given in the literature. According to Shear et al. several cases may cross the midline in the mandible, but it is unusual in maxilla (4). In our case lesion extends from 38 and crossed the midline to reach the distal aspect of 45. This is also consistent with the findings observed in literature. Radiographically, they appear as radiolucent areas often associated with complex odontome leading to the appearance of dense opacities in the cyst. Resorption of roots of adjacent teeth is a frequent finding and a very important $\mathrm{x}$-ray feature (15). Present case showed well defined radiolucency extending from 38 to 45 with root resorption of $31,32,33,41,42,44,45$ when radiograph was carefully evaluated it showed specks of opacities near apices of teeth. Presence of ghost cells are considered as characteristic but not pathognomonic for diagnosis of Calcifying odontogenic cyst. Numerous ghost cells were observed in our case and many of them have undergone calcification.

Ghost cells may undergo calcification and lose their celIular outline to form sheet like-area. Levy also supported the concept of calcification of ghost cells and held ischemia as a responsible factor. Many investigators have made effort to clarify the nature of ghost cells by employing special histochemical methods, transmission electron microscopy, and scanning electron microscopy, and various theories have been proposed without any general agreement. Gorlin et al., Ebling and Wagner, Gold, Bhasker, Komiya et al., and Regezi et al. all believed that ghost cells represent normal or abnormal keratinization. Sedano and Pindborg thought the ghost cells represented different stages of normal and aberrant keratin formation and that they were derived from the metaplastic transformation of odontogenic epithelium. Other investigators suggested or implied that ghost cells may represent the product of abortive enamel matrix in odontogenic epithelium. However, the morphology of ghost cells seems different from that of enamel matrix. Ghost cells are not unique to CGCOC, but are also seen in odontoma, ameloblastoma, craniopharyngioma, and other odontogenic tumors (8). Our case represents the classical features of calcifying odontogenic cyst, according to Praetorius et al. (3) it comes under category of Type 1(c) ameloblastomatous proliferating type, and according to Reichart (6), it comes under the category of calcifying ghost cell odontogenic cyst (CGCOC) non-neoplastic (simple cystic) variant with unicystic, plexiform arneloblastornatous proliferation of epithelial lining. Simple enucleation is sufficient treatment, and there is little risk of recurrence.

Ameloblastomatous COC microscopically resembles unicystic ameloblastoma except for the ghost cells and calcifications within the proliferative epithelium. Ameloblastomatous COC occurs only intraosseously. This subtype of $\mathrm{COC}$ is distinct from true ameloblastoma arising in COC. In contrast to ameloblastoma ex COC, the ghost cells and dystrophic calcifications are within the proliferative epithe- 
lium, which lacks histopathologic criteria as suggested by Vickers and Gorlin, and is confined to the cyst lumen. Ameloblastoma ex $\mathrm{COC}$ designates an ameloblastoma arising from the cyst lining epithelium of COC. Our review of the literature revealed only four cases (16).

Ameloblastoma ex COC occurs intraosseously, appearing as cyst-like, radiolucent lesions. Whether these tumors are potentially as destructive as typical ameloblastoma and have the same propensity for recurrence is unknown. Whether ameloblastoma ex COC should be classified as a subtype of ameloblastoma or as a subtype of COC may be open to discussion. Buchner suggested that if the COC was associated with an ameloblastoma, its behavior and prognosis would be of the same as an ameloblastoma, not COC (16).

\section{Conclusion}

Calcifying odontogenic cyst has long been recognized as a distinct clinical entity. Some authorities believe that it is more appropriately called as tumour (Dentinogenic ghost cell tumour). It can sometimes pose a diagnostic dilemma which should be diagnosed based upon vigilant comprehensive analysis of radiographic and histopathologic findings. More number of case reports is required to exactly delineate the biological behaviour of such a rare histological variant of rare odontogenic cyst.

\section{References}

1. Erasmus JH, Thompson IOC, Rensburg LV, Westhuijzen A. Central calcifying odontogenic cyst. A review of the literature and the role of advanced imaging techniques. Dentomaxillofacial Radiology 1998; 27(1):30-5.

2. Gorlin RG, Pindborg JJ, Clausen FP, Vickers RA. The calcifying odontogenic cyst - a possible analogue of the cutaneous calcifying epithelioma of Malherbe: an analysis of fifteen cases. Oral Surgery, Oral Medicine, Oral Pathology 1962; 15(10):1235-43.

3. Prætorius F, Hjørting-Hansen E, Gorlin RJ, Vickers RA. Calcifying odontogenic cyst. Range, variations and neo- plastic potential. Acta Odontologica Scandinavica 1981; 39:227-40.

4. Shear M, Speight P. Calcifying odontogenic cyst (Calcifying cystic odontogenic tumors). Cyst of the Oral and Maxillofacial Region, Blackwell Munksgaard, New York, NY, USA, 4th edition, 2007; 100-107.

5. Kramer IRH, Pindborg JJ, Shear M. Histological typing of odontogenic tumours. 2nd ed, Springer-Verlag, Berlin 1992; 7-20.

6. Philipsen HP. Keratocystic odontogenic tumour. In: Barnes L, Eveson JW, Reichart P, Sidransky D (EDS). Head and neck tumours. Pathology and Genetics. WHO Classification of tumours. IARC Press, Lyon, 2005: 306-7.

7. Fejerskov $\mathrm{O}, \mathrm{Krough} \mathrm{J}$. The calcifying ghost cell odontogenic tumor or the calcifying odontogenic cyst. J Oral Pathology $1972 ; 1: 273$.

8. Sonone A, Sabane VS, Desai R. Calcifying Ghost Cell Odontogenic Cyst: Report of a Case and Review of Literature. Case Reports in Dentistry 2011; 1-5.

9. Toida M. So-called calcifying odontogenic cyst: review and discussion on the terminology and classification. $\mathrm{J}$ Oral Pathol Med 1998; 27(2):49-52.

10. Hong SP, Ellis GL, Hartman KS. "Calcifying odontogenic cyst. A review of ninety-two cases with reevaluation of their nature as cysts or neoplasms, the nature of ghost cells, and subclassification," Oral Surgery Oral Medicine and Oral Pathology, vol. 72, no. 1, 1991; 56-64.

11. Marx RE, Stern D. "Odontogenic and nonodontogenic cysts," in Oral and Maxillofacial Pathology: A Rationale for Diagnosis and Treatment, Quientessence Publishing, Hanover Park, III, USA, 1st edition, 2003; 607.

12. Altini M, Farman AG. "The calcifying odontogenic cyst: eight new cases and a review of the literature". Oral Surgery Oral Medicine and Oral Pathology 1975; 40:751-9.

13. Neville BW, Damm DD, Allen CM, Bouquot JE. Odontogenic cysts and tumors," in Oral and Maxillofacial Pathology," W. B. Saunders, Philadelphia, $\mathrm{Pa}, \mathrm{USA}, 2^{\text {nd }}$ edition, 2002; 590.

14. Kenzevic G, Sokler K, Kobler P, Manojlovic S. Calcifying odontogenic cyst - Gorlin's cyst - report of two cases. Coll Antropol 2000; 28(1):357-62.

15. Patil A. Calcifying Odontogenic Cyst - A Case Report. JIDA 2010; 4(12):547-549.

16. Nosrati K, Seyedmajidi M. Ameloblastomatous Calcifying Odontogenic Cyst: A Case Report of a Rare Histologic Variant. Arch Iranian Med 2009; 12 (4):417-20. 